\title{
Integrating Roy's Adaption Model in Care of Palliative Clients-A Case Scenario Analysis
}

\author{
Sarmad Muhammad Soomar* and Khalid Ahmed \\ Aga Khan University School of Nursing \& Midwifery, Pakistan
}

Submission: July 13, 2018; Published: July 17, 2018

*Corresponding author: Sarmad Muhammad Soomar, School of Nursing \& Midwifery, Aga Khan University School of Nursing \& Midwifery,

Pakistan, Email: soomarsarmad@gmail.com

Abstract

Palliative setting is always a challenging task for health care providers, especially nurses as direct care givers. It involves emotions and makes nurses relatable in care while assessing client's condition. Palliative is much more patient focused, so nurse has to comply with all their suffering and pain and help them to cope maximally from that. The assessment not only gives the presence of physical pain, but psychosocial and economic stressors as the composite factors for patient's stress. The paper generally discusses these domains of palliative client's health through analysis of a witnessed case scenario. Also, describes and analyze the scenario by integrating it with the components of Roy's adaption model and highlights the need of addressing these domains in palliative nursing care.

\section{Introduction and Case scenario}

Role of nurses has been evolved since years. Nurses have been competent enough in terms of working in all kind of setting they are assigned to. From women to men, young to old and even from a newborn to a dying client, nurse has all the skills, knowledge and competency to deal with those incidences and problems. Not only the areas of concern, but underlying status of patient that is potentially compromised, is also under nurse's observation. It becomes more crucial and essential for nurses when they work in delicate settings like end of life or palliative care [1]. They have to take care the patient in terms of improving his/her quality of life detoriated because of terminal illness. Nurses are advised to broaden their assessment and enhance their skills in practice to prevent further loss and to ensure maximum care and treatment [1]. Working in a palliative setting is always a challenging task. We also had similar feeling while we were taking care of patients with terminal illness during my rotation. All and all the work goes beyond the job. It involved our emotions and made us cry and feel sad, after assessing client's condition. One must have a mixed feeling to either carry out tasks or not. Palliative is much more patient focused, so nurse must comply with all their suffering and pain and help them to cope maximally from that. As we describe our clinical experience at one of the private cancer hospitals in Karachi. We also possessed same kind of feelings that led us in confusion, sadness, emotional instability and somewhere hopeful to predict a positive outcome of future.

We worked and served our time with a young male patient of 17 years, having a third stage colorectal cancer. During history taking he mentioned severe pain in lower abdomen with episodes of heavy vomitus. Also, due to severity of these clinical manifestations the young male was treated prior at a small hospital in his village setup. He was referred into a tertiary care hospital, after suggestion of few investigations that were necessary to rule out the cause of the present condition. Another reason to move this hospital was unaffordability of treatment over there. In addition, he mentioned about weakness that he bears since many months due to this condition. He was more concerned about his diseases, regimen, and stability of health along with minimal expenses. In depth discussion lead to information about altered relations in family that is according to patient "no one support me, I have to manage all this physical pain and loss of money, I can't rely on my father as he is a mean natured man who scolds me and tortures me for money even on minor health ailments". Recalling the clinical experience justified the basic realities of life on us that how troublesome is for people to spent money on something that give them better life in years ahead. We had a helpless kind of feeling that we could have something that can help them to pull out of these issues. As we evaluate the experience and discussed among each other, we were able to distinguish and highlight presence of physical aspects of health along with underpinning psychological aspect with it. Bearing with intolerable pain and continuous episodes of heavy vomiting are prime observed physical issues and burden increased due to ill health, financial constraints, ineffective family relations and behaviors could be termed as psychological constrains bear by the young client.

\section{Discussion}

Comprehending and evaluating the significant findings of client's case in terms of current literature discloses the following 
facts. The significant increase of colorectal cancer in young adults especially in men has been significantly seen [2]. The prominent reasons that came to the front were listed as inheritance, imbalanced nutrition, constipation, inflammatory bowel conditions, obesity, and sedentary lifestyle, long hours of sitting for work or education purpose, alcohol or smoking and may be due to any radiation exposure [3]. Pain and vomiting are the major symptoms of this condition. In worst cases clients may experience heavy bleeding at the anal site. Pain is the highly disturbing clinical manifestation experienced by majority of young people during the advancement or treatment of cancer. This is something highly observed while end of life period of oncology clients. Despite of been high consideration, literature reflects that pain is most of the time poorly managed in clients with cancers [4]. Furthermore, the psychological burden on cancer clients is imposed due to day by day increase in cost of care. Advancement in treatments in comparison of treatment that used to be there five to seven years ago has a vast difference. The costs of that regimen are also different because of inflation [5]. In addition, relationship issues can lead to other kind of psychological stress on client and beloved ones. Cancer patients' treatment or care might increase the chance of altered family relationships or trigger transformed behaviors among relatives and other significant family members [6].

\section{Integration with Roy's adaptation model}

Considering the portions from the mentioned case study are likely to be categorized under few basic meta paradigms of Roy's adaptation model [7] (Figure 1). According to the theory

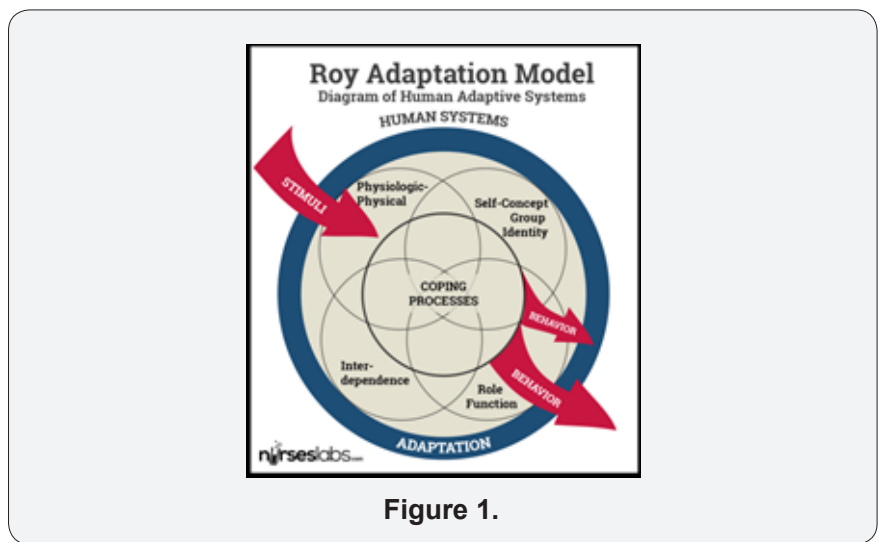

a) Environment is the portion which is full of stimuli and those are of various kind.

b) The patient itself is the adaptive system.

c) Nursing is the system that promotes adaptations.

d) Health is the outcome of that adaption.

In the above case scenario, the focal or immediate stimuli was patient's health, contextual stimulus was financial constrain and residual may include other remaining stressors of life like altered family relations. Coping mechanisms are categorized as either individual or group; in this case it goes for an individual coping system through natural means of body like chemicals or hormones (regulator). In addition, aspects developed through self-judgment of situations and learning through analysis of stressful events can enhance coping (cognator). Next comes the adaption modes. This includes

a. physiologic,

b. self-concept,

c. role function,

d. interdependence.

The client and the family couldn't access basic health care facilities. They have a one room house with adequate lightning and aeration. There was no specific concept of balanced nutrition; whatever was available was utilized. Patient's primary complains were pain and vomitus, secondary complains were related to constipation and weakness. Six to seven hours sleep at night and half an hour naps in afternoon were practiced. No significant concept of daily exercise was evident in history. Family dynamics has problems and they viewed themselves as weak to bear the hospital expenses to ensure quality healthcare. Family roles were less observed and seemed less supportive due to conflicts among patient and his father. No other significant family members were present and involved in patient health decisions. Interaction of family with community was not strongly evident through history. According to the concepts of Roy's adaptation model: Positive stimuli + Positive coping and modes of adaption = Effective adaption. In mentioned experience of our client the adaption couldn't be categorized as effective due to lack of positive coping skills. Although below recommendations could be utilized to enhance the portion of "Nurse's role" in terms of building capacity in client to promote and encourage positive adaption. Nurse plays significant role in gaining patient's positive health outcomes. Nurse promotes adaption in client with long terms illness. Strengthening nurse's role in palliative care can affect the promotion of positive adaption in palliative client. This can directly impact on client's both physiologic and psychological aspects of health.

\section{Conclusion and Recommendations}

In conclusion, nursing care enhanced on basis of clients' physical \& psychological domains in palliative care is an area of high importance. In terms of addressing patient's chief complaint and associated problem that may hinder his very important aspects of life, these roles have huge importance. More quality institutions should be developed so that survival rate of patients should be ensured with quality of life care. Also, a proper and organized plan for counseling can improve their service delivery skills. Advance education of nurses in palliative care can enhance their knowledge and skills further. Research on family and economic issues with cancer clients could be on to do lists of healthcare providers, to ensure better future outcomes in oncology care. Master trainers of adolescent health needs could be looped into for cross functional learning and providing better care to young clients diagnosed with cancer. 


\section{References}

1. World Health Organization (2017) WHO Definition of Palliative Care.

2. Siegel RL, Jemal A, Ward EM (2009) Increase in Incidence of Colorectal Cancer among Young Men and Women in the United States. Cancer epidemiology biomarkers \& prevention 18(6): 1695-1698.

3. Mayo Clinic (2017) Colon Cancer - Symptoms and Causes. Patient Care \& Health Information.

4. Stinson JN, Jibb LA, Nguyen C, Nathan PC, Maloney AM, et al. (2013) Development and Testing of a Multidimensional iPhone Pain Assessment Application for Adolescents with Cancer. J Med Internet Res 15(3): 51.
5. Yabroff KR, Lund J, Kepka D, Mariotto A (2011) Economic Burden of Cancer in the United States: Estimates, Projections, and Future Research. cancer epidemiology biomarkers \& prevention 20(10): 2006-2014.

6. Northouse L, Williams A, Given B, McCorkle R (2012) Psychosocial Care for Family Caregivers of Patients with Cancer. Journal of Clinical Oncology 30(11): 1227-1234.

7. Parker ME (2005) Sister Callista Roy's Adaptation Model and Its Applications. In Nursing theories and nursing practice ( $2^{\text {nd }}$ edn.), pp. 268-280.

\section{Your next submission with Juniper Publishers will reach you the below assets}

- Quality Editorial service

- Swift Peer Review

- Reprints availability

- E-prints Service

- Manuscript Podcast for convenient understanding

- Global attainment for your research

- Manuscript accessibility in different formats

( Pdf, E-pub, Full Text, Audio)

- Unceasing customer service

Track the below URL for one-step submission https://juniperpublishers.com/online-submission.php 